\title{
THE ALUMINIUM $K \beta$-BAND STRUCTURE OF ANDALUSITE, SILLIMANITE AND KYANITE
}

\author{
JAAKKo SiIVOLA
}

\begin{abstract}
Sirvola, JAAKko 1971: The aluminium $K \beta$-band structure of andalusite, sillimanite and kyanite. Bull. Geol. Soc. Finland 43, 1-6.

The paper describes the results obtained from the $\mathrm{x}$-ray $K \beta$-band spectra of $\mathrm{Al}$ for andalusite, sillimanite and kyanite. The fine structure of the aluminium $K \beta$-band is correlated with the crystal structure of these minerals. It is considered that the difference between the energies of the $K \beta$ - and $K \beta^{\prime}$-lines depends on the distance between the aluminium and oxygen atoms. The energy differences between the $\mathrm{Al}$ and $\mathrm{O}$ atoms in andalusite, sillimanite and kyanite have been determined. The energy differences show a linear correlation to the known interatomic distances.
\end{abstract}

Jaakeo Siivola, Geological Survey of Finland, Otaniemi, Finland.

\section{Introduction}

The electron microprobe is no longer used merely for making chemical analyses. It has proved to be a powerful tool also in the field of $\mathrm{X}$-ray physics. The increasing interest in the application of microprobe techniques to problems dealing with the crystal structures of minerals led to studies of the shape and energy of different X-ray spectral lines. The interatomic distances, coordination of atoms, chemical bonding effects etc. have their influence on the spectral lines. Special attention has been paid to the coordination of aluminium and silicon in silicate minerals by several authors, e.g. Baun \& Fischer 1964, Koffman \& Moll 1965 and Läuger 1968. Recently Dodd \& Glenn (1968, 1969) combined the $\mathrm{X}$-ray $K \beta$-spectrum with the so- called molecular orbital (MO) theory in order to explain the differences between the spectral lines from various aluminosilicates.

The purpose of the experimental work reported in this paper is to study the $\mathrm{fine}$ structure of the $\mathrm{Al} K \beta$-band spectra as recorded from andalusite, sillimanite and kyanite. Their crystal structures are accurately known (Burnham \& Buerger 1961, Burnham 1963 a, 1963 b). The total chemical composition is identical $\left(\mathrm{Al}_{2} \mathrm{SiO}_{5}\right)$ for each mineral. Thus the differences found in the $\mathrm{X}$-ray spectra reflect the differences in the crystal structures of these minerals.

\section{Experimental}

The measurements reported in this paper were performed by using an electron probe micro- 


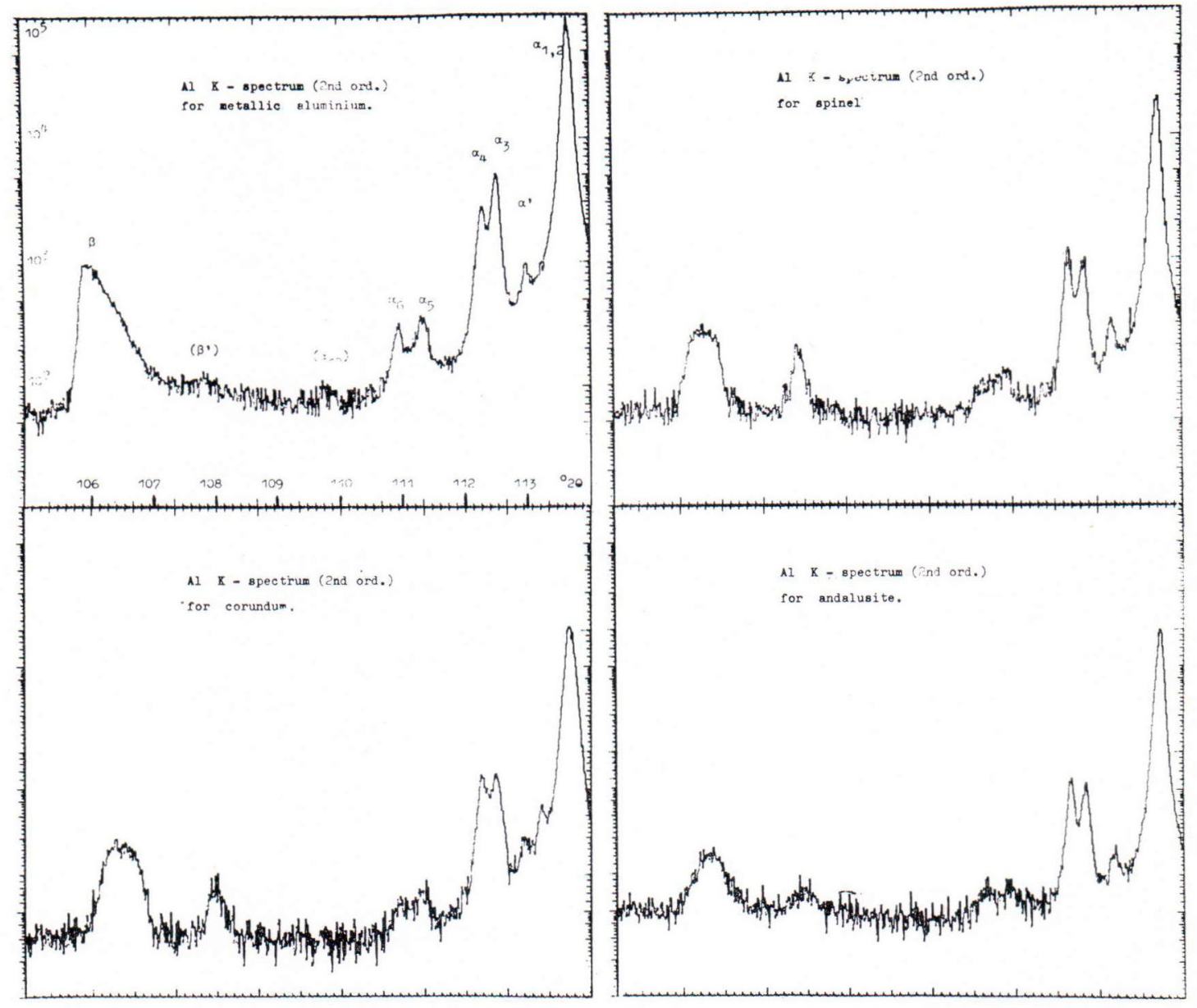

Fig. 1. The aluminium $\mathrm{K}$-spectrum (2nd ord.) for metallic aluminium, corundum, spinel and andalusite.

analyser model GEOSCAN. Andalusite, sillimanite and kyanite investigated here are natural minerals from Al-rich schists in the Salla area, Northern Finland.

(i) The principal features of the whole Alspectrum were recorded from different kinds of samples (Fig. 1). (The low energy side of the $K \alpha_{1,2}$-line and the high energy side of the $K \beta$ line are omitted in this figure). The $\mathrm{X}$-ray spectrometer was driven with a special step scanning device developed in the laboratory of the Geological Survey. The measured pulses were punched on an 8-channel tape. The final spectra were drawn by using an Elliot 803 computer. (ii) The $K \beta$-band of aluminium for andalusite, sillimanite and kyanite as well as for nepheline and topaz was recorded under the following working conditions: Accelerating voltage $20 \mathrm{kV}$, specimen current $400 \mathrm{nA}$, analysing crystal Mica, flow counter, analysed lines 2 nd order Al $K \beta$ and $K \beta^{\prime}$, range $108^{\circ} 30^{\prime}$ to $105^{\circ} 30^{\prime} 2 \Theta$.

In order to find out the basic shapes of the lines measured the first runs were performed using $3^{\prime}(2 \Theta)$ steps and 100 second counting intervals. At critical points improved statistics was achieved by decreasing the step intervals and increasing the couting intervals to 200 seconds. Finally, repeated runs were performed 
in the region of $106^{\circ} 50^{\prime}$ to $106^{\circ} 08^{\prime}$ using $1^{\prime}$ steps and 200 second counting intervals.

(iii) The Co $L \alpha_{1,2}$-line was used for calibration. The working conditions were as above and the range of the measurement from $107^{\circ} 30^{\prime}$ to $106^{\circ} 00^{\prime} 2 \Theta$. The wavelength of the calibration line was taken as $15.975 \AA$ which corresponds to an energy of $776 \mathrm{eV}$. The position of this line is $106^{\circ} 38^{\prime}$ in a Bragg angle scale when using a Mica crystal analyser with 2 d of $19.92 \AA$.

\section{Results}

Figure 1 shows the Al K-spectrum of a few materials. The position of the unresolved $K \alpha_{1,2}$ line varies slightly with the composition of the sample. Between the $K \alpha_{1,2^{-}}$and $K \beta$-lines a number of so-called satellite lines are recorded. The intensity ratio $K \alpha_{3}: K \alpha_{4}$ is strongly affected by the chemical composition of the sample (cf. Baun \& Fischer 1964). The shape of the Al $K \beta$-line in metallic aluminium indicates a band of free electrons. The spectra for corundum, andalusite and spinel show that in these minerals the $K \beta$-line results from ordered electron combinations. The $K \beta$-line is generated by $\mathrm{M}-\mathrm{K}$ shell electronic transitions. Aluminium is one of the third period elements. Its M-shell electrons are those which participate in chemical bonds. Thus, distortions of M-shell electrons are visible in the corresponding $\mathrm{X}$-ray emission spectrum.

Figure 2 presents the Al $K \beta$-band spectra for andalusite, sillimanite and kyanite. The corresponding spectra for topaz and nepheline are included for comparison. The differences in the shapes of the $K \beta$-lines are distinct. Andalusite and sillimanite spectra resemble each other. The spectrum for kyanite differs a great deal from those of the forementioned minerals. The $K \beta$-line has been split into two parts with a clear minimum between two maxima. The $K \beta$ spectrum for topaz is basically similar to that for kyanite. The nepheline spectrum shows a symmetrical $K \beta$-line with a small hump at the

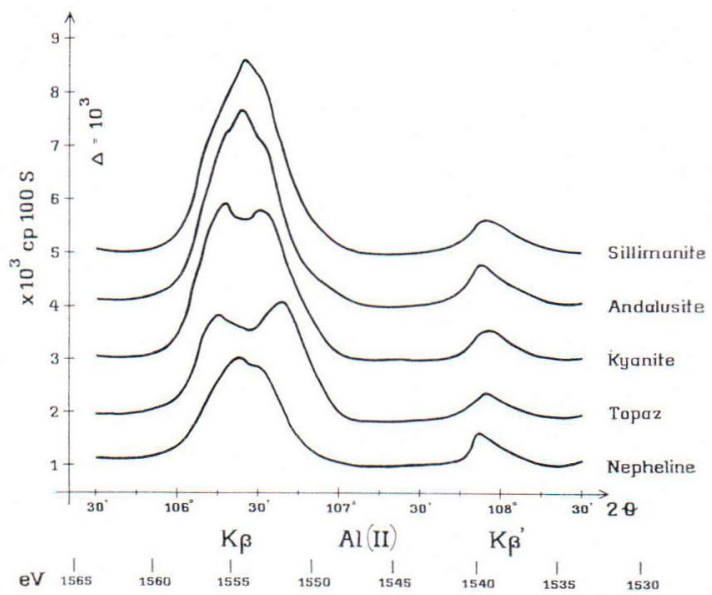

Fig. 2. The aluminium $K \beta$-band spectrum for sillimanite, andalusite, kyanite, topaz and nepheline.

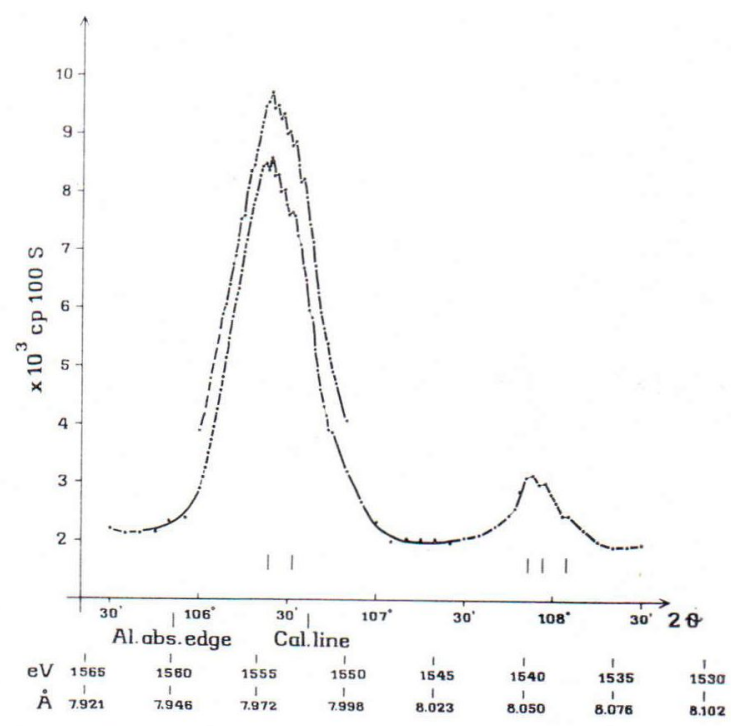

Fig. 3. The aluminium $K \beta$-band spectrum for andalusite. The position of the assumed line components and part of the repeated run are also shown.

top of the peak, whereas the $K \beta^{\prime}$-line for nepheline is very unsymmetrical in shape.

The results recorded by using improved statistics are presented in Figures 3, 4 and 5. Also included are part of the spectra obtained by the repeated runs and the position of the calibration 


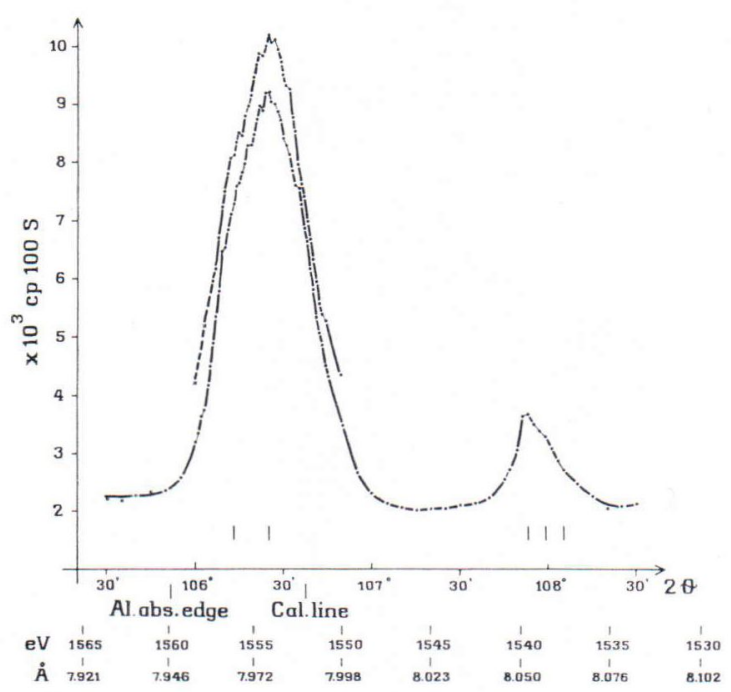

Fig. 4. The aluminium $K \beta$-band spectrum for sillimanite. The positions of the assumed line components and part of the repeated run are also shown.

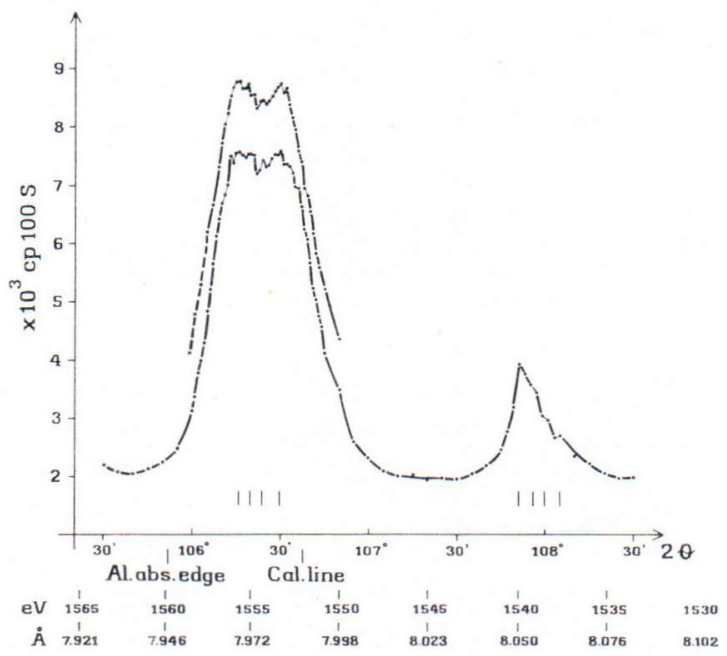

Fig. 5. The aluminium $K \beta$-band spectrum for kyanite. The positions of the assumed line components and part of the repeated run are also shown.

line, Co $L \alpha_{1,2}$. The shape of each $K \beta$-line is slightly reduced when compared with those presented in Figure 2. According to these profiles it is obvious that the $K \beta$-line of these minerals consists of several components. Also the $K \beta^{\prime}$-lines consist of different components as is clearly shown by the figures.

The position (2 $\Theta$ ) of the $\mathrm{Al} K \beta$-line at $2 / 3$ height is as follows: $106^{\circ} 24.5^{\prime} \pm 0.5^{\prime}$ for andalusite, $106^{\circ} 24.5^{\prime} \pm 0.5^{\prime}$ for sillimanite and $106^{\circ} 24.0^{\prime}$ $\pm 0.5^{\prime}$ for kyanite. The line width $(2 \Theta)$ at $2 / 3$ height is $23^{\prime}, 25.5^{\prime}$ and $32^{\prime}$ (or 3.9, 4.3 and $5.4 \mathrm{eV}$ ), respectively. The corresponding line widths relative to andalusite are $1,1.11$ and 1.39 , respectively. A common feature in these minerals is that there is no shift regarding the position of the $K \beta$-line.

\section{Discussion}

The $K \beta$-band spectra of metallic magnesium, aluminium and silicon show only an asymmetrical $K \beta$-line (cf. Dodd \& Glenn 1968). This spectrum originates from $\mathrm{M}-\mathrm{K}$ shell transitions. The $K \beta$-line itself is ascribed to a $3 \mathrm{p}-1 \mathrm{~s}$ electronic transition. Thus, the origin of the $K \beta^{\prime}$-line remains unexplained. The $K \beta^{\prime}$-line has been explained as a cross $\mathrm{tr}$ a n sition of an oxygen (L) 2 p electron to an aluminium (K) 1s orbital ( $c f$. Läuger 1968). The evidence for the existence of this $\mathrm{X}$-ray quantum is revealed by every $\mathrm{X}$-ray spectrum recorded for compounds containing $\mathrm{Al}$ and $\mathrm{O}$ atoms ( $c f$. Läuger op. cit.,; Dodd \& Glenn 1968, 1969; this paper Fig. 1). The intensity of the $K \beta^{\prime}$-line is small compared with that of the $K \beta$ line. The energy of the $K \beta^{\prime}$-line is lower than that of the $K \beta$-line. The difference between the energies of the $K \beta$ - and $K \beta^{\prime}$-lines is here considered to reflect the distance between the aluminium and oxygen atoms.

Following this theory, Tables 1 and 2 and Figure 6 summarise the results obtained in this study. It is concluded that when the distance between the $\mathrm{Al}$ and $\mathrm{O}$ atoms is small the energy difference between the corresponding $K \beta$ - and $K \beta^{\prime}$-lines is great and vice versa. In Table 2 the $\mathrm{Al}-\mathrm{O}$ interatomic distances are ordered according to the increasing bond length in andalusite, sillimanite and kyanite. The main peak of the 
TABLE 1

The wavelengths and the energies of the $\mathrm{X}$-ray lines from $K \beta$-band spectra for andalusite, sillimanite and kyanite.

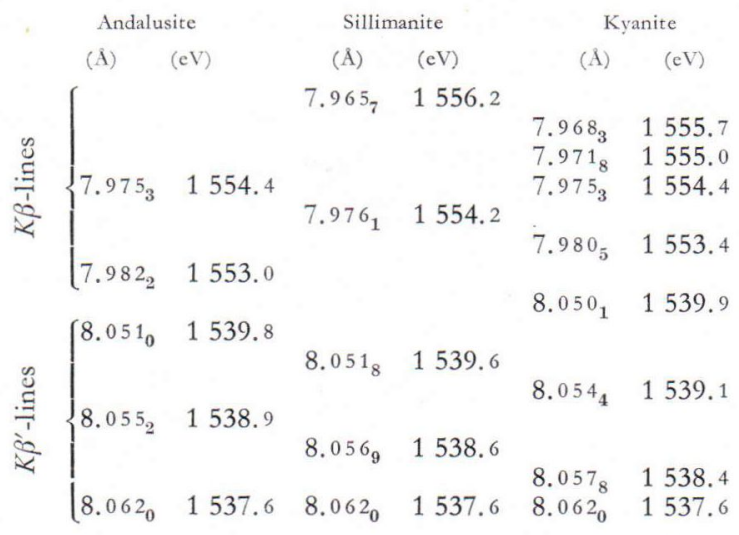

TABLE 2

The Al-O interatomic distances $(\AA)$ and the $\mathrm{Al}-\mathrm{O}$ energy differences $(\mathrm{eV})$ in andalusite, sillimanite and kyanite.

\begin{tabular}{|c|c|c|c|c|c|}
\hline \multicolumn{2}{|c|}{ Andalusite } & \multicolumn{2}{|c|}{ Sillimanite } & \multicolumn{2}{|c|}{ Kyanite } \\
\hline$\AA$ & $\mathrm{eV}$ & $\AA$ & $\mathrm{eV}$ & A & $\mathrm{eV}$ \\
\hline 1.816 & \multirow{4}{*}{16.8} & 1.721 & 18.6 & 1.814 & 18.1 \\
\hline 1.818 & & & & & \\
\hline \multirow[t]{2}{*}{1.818} & & 1.758 & 17.6 & 1.843 & 174 \\
\hline & & & & 1.843 & $1 / .4$ \\
\hline 1.829 & \multirow{2}{*}{15.5} & 1.800 & 16 & & \\
\hline 1.829 & & 1.800 & 10.6 & 1.853 & 17.3 \\
\hline \multirow[t]{2}{*}{ 1. 843} & \multirow[t]{2}{*}{15.4} & 1.861 & \multirow{2}{*}{16.6} & 1.860 & 16.8 \\
\hline & & 1.861 & & & \\
\hline \multirow[t]{2}{*}{1.886} & \multirow[t]{2}{*}{14.6} & & \multirow{3}{*}{15.6} & 1.883 & \\
\hline & & 1.919 & & 1.885 & 16.6 \\
\hline $\begin{array}{l}1.892 \\
1.892\end{array}$ & \multirow[t]{2}{*}{14.1} & 1.919 & & & \\
\hline \multirow{16}{*}{$\begin{array}{l}2.085 \\
2.085\end{array}$} & & 1.957 & \multirow{16}{*}{14.6} & $\begin{array}{l}1.891 \\
1.892\end{array}$ & \\
\hline & \multirow{15}{*}{13.2} & 1.957 & & 1.894 & 16.6 \\
\hline & & & & 1.894 & \\
\hline & & & & 1.894 & \\
\hline & & & & 1.907 & 16.0 \\
\hline & & & & 1.915 & 15.9 \\
\hline & & & & 1.920 & 15.8 \\
\hline & & & & 1.930 & 15.8 \\
\hline & & & & 1.936 & \\
\hline & & & & 1.939 & 15.3 \\
\hline & & & & 1.939 & \\
\hline & & & & 1.959 & 15.1 \\
\hline & & & & 1.971 & 15.0 \\
\hline & & & & 1.979 & 14.5 \\
\hline & & & & 1.992 & 14.3 \\
\hline & & & & 1.998 & 13.5 \\
\hline
\end{tabular}

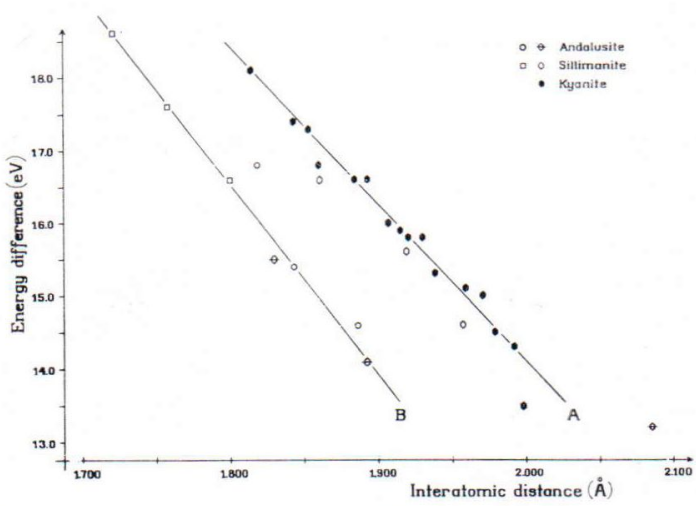

Fig. 6. A plot of the energy difference versus the interatomic distante. The points corresponding to the octahedrally coordinated aluminium in andalusite, sillimanite and kyanite are shown by hexahedrons. The points corresponding to the tetrahedrally coordinated aluminium in sillimanite are marked with squares and those corresponding to the five - coordinated aluminium in andalusite are shown by rings.

$K \beta$-band, the $K \beta$-line, is assumed to be divided into two components in the andalusite and sillimanite spectra and into four components in the kyanite spectrum. The $K \beta^{\prime}$-line splits into three, three and four components, respectively (see Figs. 3, 4 and 5). Table 1 shows the wavelengths and energies of these components of the $\mathrm{X}$-ray spectra for andalusite, sillimanite and kyanite.

Table 2 presents the $\mathrm{Al}-\mathrm{O}$ interatomic distances (in $\AA$ ) and the energy differences (in $\mathrm{eV}$ ) in andalusite, sillimanite and kyanite. The term »energy difference» is used as a measure for the distance of aluminium and oxygen atoms as was stated above. The values of the energy differences are obtained by subtracting the energy of each $K \beta^{\prime}$-line from each $K \beta$-line energy (Table 1$)$. The interatomic distances were collected from the refinements of the crystal structures of andalusite by Burnham \& Buerger (1961), sillimanite by Burnham (1963 a) and kyanite by Burnham (1963 b). The numerical values given in Table 2 have been plotted in Figure 6 to show the energy difference versus the interatomic distance. A linear correlation between the energy difference and the interatomic distance of the octahedrally 
coordinated aluminium in kyanite is evident. The points corresponding to the octahedral Alcoordination in sillimanite are arranged almost on the same line (line A in Figure 6). The points corresponding to the tetrahedrally coordinated aluminium in sillimanite are situated on the other line (line B in Figure 6) nearly parallel to line A. The $\mathrm{AlO}_{6}$-octahedron of the andalusite structure is strongly deformed. This fact is also visible in Figure 6. The point which corresponds to the $2.085 \AA$ interatomic distance is situated near the tail of line A whereas those corresponding to the other interatomic distances of this octahedron lie on line $\mathrm{B}$. The point reflecting the shortest $\mathrm{Al}-\mathrm{O}$ distance in the $\mathrm{AlO}_{5}$-group of the andalusite structure lies between lines $A$ and $B$ and the rest of them are on line B. - Thus the numerical values of the energy difference can be correlated to the known crystal structures of andalusite, sillimanite and kyanite.

As to the intensity of the $K \beta^{\prime}$-line, the increasing value of the ratio $K \beta^{\prime}: K \beta$ is considered to reflect the increasing covalent nature of the chemical bond ( $c f$. Läuger 1968). The intensity ratio $K \beta^{\prime}: K \beta$ (areas) is $11.4 \%$ for andalusite, $12.5 \%$ for sillimanite and $14.6 \%$ for kyanite (according to the peak height $17.6 \%, 23.5 \%$ and $34.8 \%$, respectively).

In summary it can be concluded: The method used offers the possibility of combining X-ray spectral results with the crystal structure and chemistry. The fine structure of the $K \beta$-band lines of the $\mathrm{X}$-ray spectrum can be correlated with the crystal structure of the mineral. On the scale used, in Figure 6, the value for the energy difference varies linearly with the $\mathrm{Al}-\mathrm{O}$ interatomic distance. Kyanite proves to have the highest covalent stage of chemical bonds. On the contrary, andalusite has a rather low covalent nature in chemical bonds.

Acknowledgements - The author wishes to express his gratitude to Prof. G. Graeffe, Dr. M. Linkoaho, and Dr. A. Vorma for many fruitful discussions, to Prof. A. Siivola for critical reading of the manuscript, to Miss Karen Dahl and Mr. E. Halme for preparing the graphs ready for printing.

\section{REFERENCES}

Baun, W. L. and Fischer, D. W. (1964) The effect of valence and coordination on $K$ series diagram and nondiagram lines of magnesium, aluminium and silicon.-Advances in x-ray analysis, Vol. 8, 1965, pp. $371-381$.

Burnham, C. W. (1963 a) Refinement of the crystal structure of sillimanite. - Z . für Kristallographie, Bd. 118, S. $127-148$.

- (1963 b) Refinement of the crystal structure of kyanite. - Ibid., Bd. 118, S. 337-360.

- and Buerger, M. J. (1961) Refinement of the crystal structure of andalusite. - Ibid., Bd. 115, S. 269-290.

Dodd, C. G. and GlenN, G. L. (1968) Chemical bonding studies of silicates and oxides by $\mathrm{x}$-ray $\mathrm{K}$-emission spectroscopy. - J. of Applied Physics, Vol. 39, pp. $5377-5384$.

- (1969) A survey of chemical bonding in silicate minerals by $\mathrm{x}$-ray emission spectroscopy. - Am. Min., Vol. 54, pp. 1299-1311.

Koffman, D. M. and Moll, S. H. (1965) The effect of chemical combination on the $\mathrm{K} x$-ray spectra of silicon. - Advances in x-ray analysis, Vol. 9, 1966, pp. $323-328$.

LÄUGER, K. (1968) Über den Einfluss der Bindungsart und der Kristallstruktur auf das K-Röntgenemissionsspektrum von Aluminium und Silizium. - Dissertation, Ludwig-Maximilians-Universität, München.

Manuscript received, June 15, 1970. 